The Employers' Liability Insurance Associations have acted consistently in accordance with the favourable results obtained in a centre for spinal cord injuries which is integrated into an accident hospital.

New centres are being built and out-dated departments are to be rebuilt or extended.

\title{
THE ORGANISATION OF A SPINAL INJURIES UNIT AT ROYAL PERTH HOSPITAL, PERTH, WESTERN AUSTRALIA
}

\author{
G. M. BedBrook, O.B.E., M.S., F.R.C.S., F.R.A.C.S. \\ Department of Paraplegia, Royal Perth Hospital, Perth, Western Australia
}

WITH the development of spinal units in many cities of the world, there will be variety in methods of inauguration and organisation of services that have become accepted parts of hospitals or medical centres. This mode has largely depended on the surgeon or physician who has had the primary interest in such patients. Thus the neurosurgeon, orthopaedist, urologist and physical medicine physician will be found in the vanguard of that ever-increasing group who will care for such patients.

\section{HISTORICAL}

Australia now has four well-developed centres. Of these, the centre in Perth, Western Australia, developed first in 1954, followed by Melbourne, Victoria, in 1956. Each developed differently.

In Perth, during 1953, it became apparent that a number of paraplegics were hospitalised in various wards of Royal Perth Hospital. With the co-operation and consent of senior members of the clinical staff, to whose vision Western Australia can be for ever grateful, and with the help of the medical superintendent, the then in-patients were collected together into an orthopaedic ward at the Infectious Diseases Branch at Shenton Park-later to become the Royal Perth Rehabilitation Hospital.

As a member of the orthopaedic department, the author was asked to assume clinical responsibility, and so a unit was inaugurated as part of the orthopaedic department. All acute cases were admitted to the main orthopaedic department wards at the parent hospital and transferred at the end of five or six weeks to Shenton Park for further rather limited physical care and rehabilitation which was then available. However, a start had been made. Eventually, two old wards were occupied, and rapidly 20 beds were in use. This unfortunate division of the unit remained until 1963-64, when improved facilities (theatres, laboratories, $\mathrm{X}$-ray) allowed the reception of acute cases at Shenton Park.

By mutual arrangement, and with the help of the Australian Medical Association, by 1956-67 all cases of spinal injuries in Western Australia were directed to the unit, so that a really State unit was established.

Steady growth of the unit resulted in the independence of the unit by $1957-58$ 
after a visit by Sir Ludwig Guttmann. The Board of Management of Royal Perth Hospital expended considerable finance in an attempt to modernise the old buildings, but by I96I it was clear that a new block was needed, and thus a 40-bed air-conditioned block was constructed in 1962 and opened in November 1963.

Great attention in the design was paid to the space required by spinal cases and the proper arrangement of wards and treatment areas. This was only finally decided after experimental toilet areas and teaching rooms had been added to the old buildings. The final design was worked out by the author and his staff who had worked in the old buildings, and only then given to an architect to construct.

In the new building there is a two-bed acute intensive care unit with all the facilities needed for the acute care of quadriplegics needing respiratory assistance.

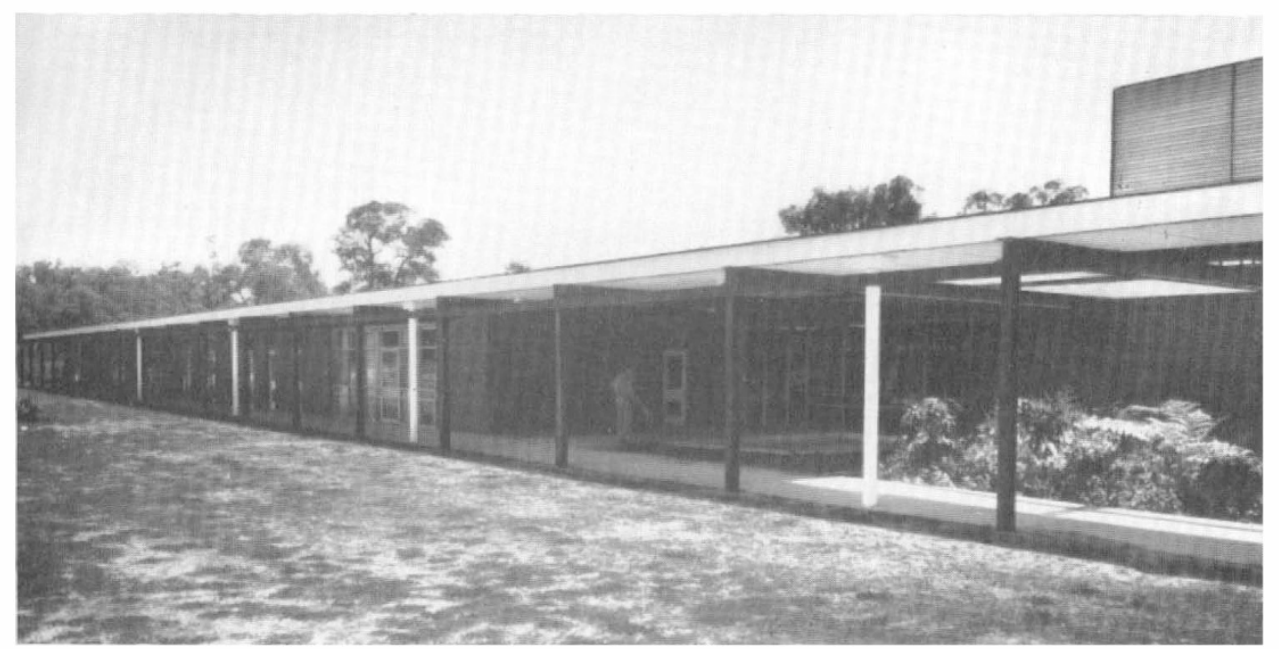

FIG. I

New Spinal Injuries Unit at Shenton Park Annexe (now Royal Perth Rehabilitation Hospital).

Over a Io-year period, increased facilities, which included a modern therapy block, were added to the hospital so that today Royal Perth Rehabilitation Hospital is a modern hospital caring for many groups in need of rehabilitation, e.g. orthopaedic, hemiplegic, rheumatoid arthritics and neurosurgical cases; with provision for acute care areas when needed.

Medical responsibility slowly improved during the Io years of expansion. Much help was obtained from consultant members of Staff, especially in urology and plastic surgery, with occasional assistance from members of other specialities. Administratively, a number of senior colleagues supported the author in the steady improvement of standards.

The unit staff in the early years was limited to the author, members of nursing staff, a resident medical officer, and a physiotherapist. Later an occupational therapist was acquired, then a social worker, and a secretary. Basically, this team remains today, although considerably expanded. 


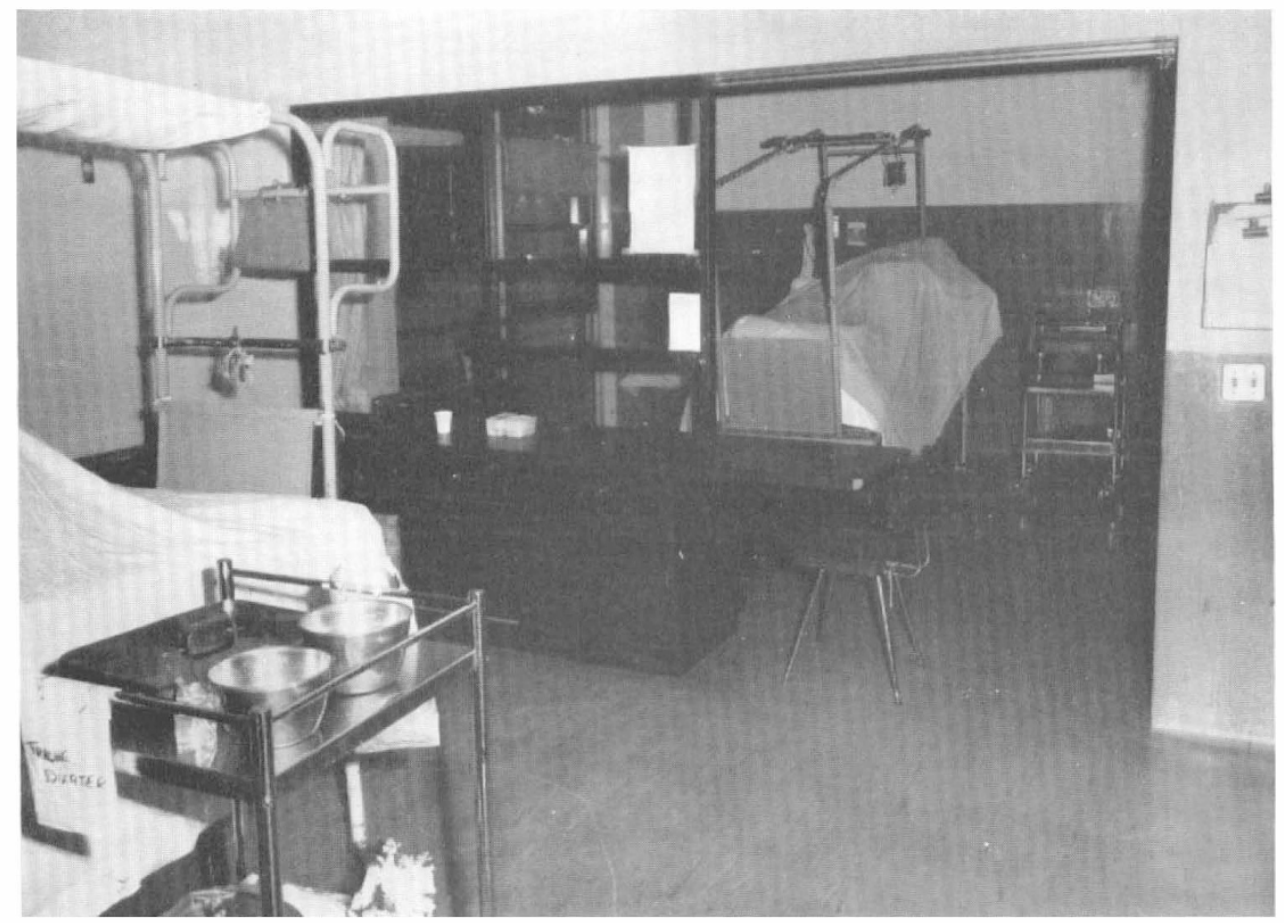

FIG. 2

Two-bed Intensive Care Unit.

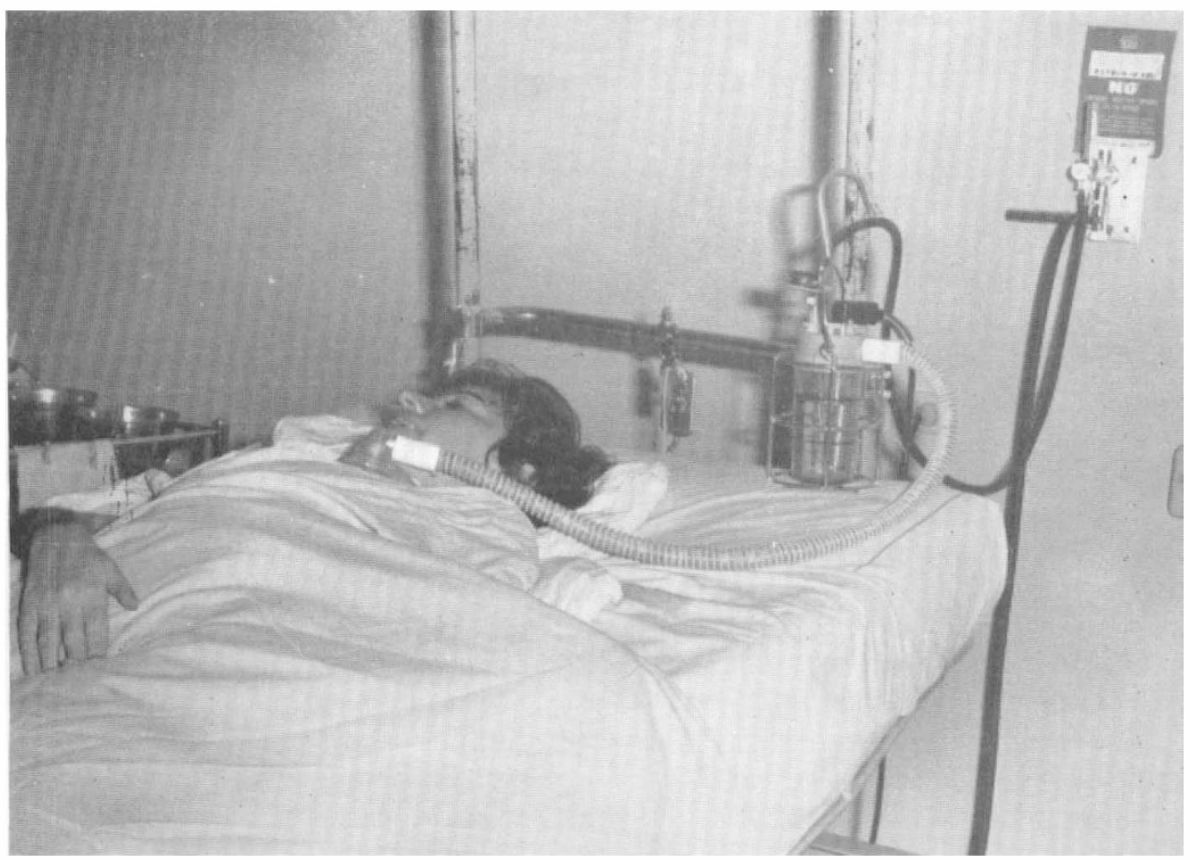

FIG. 3

Patient in Intensive Care Unit. 


\section{PRESENT ORGANISATION}

At the time of writing, the new building has been in use for almost four years and the design has proved to be adequate. All care of paraplegics is concentrated in this building, both for the in-patient and out-patient. An out-patient service is, of course, essential.

Two indivisible teams of medical personnel and medico-ancillary personnel work in the overall management of these disabled patients. The first team is a medical one consisting of a unit group and a consultant group. This group is directly under the administration of a Director, or Head of Department, an assistant director, and a junior consultant. These consultants are part-time salaried officers, two of whom are orthopaedic surgeons, the other being a general surgeon. However, in principle, this is not important. Of much more importance is the availability of well-qualified and well-trained consultants who have a particular interest in spinal paralysis as a speciality in itself. One day this individuality will be recognised in Australia, but this is still some distance away.

An additional consultant is the urologist, who also works part-time. A neurosurgeon, general surgeon, and plastic surgeon are consulted as required.

Since 1965 the part-time services of a clinical psychologist have been available to the unit. Such services are becoming increasingly integrated in the rehabilitation goals of the unit, and include psychological testing of the intellectual and personality functioning of patients, plus interviews with parents of patients. Such data are used to help patients clarify their post-accident reactions in the individual counselling situation and, more recently, in weekly group psychotherapy sessions. Separate staff discussion sessions are held, where the overall aim is to provide an appreciation of the personality of the patient in relation to rehabilitation goals.

The remainder of the medical team consists of a registrar, who is a senior house medical officer, and two resident medical officers.

The second team is a medico-ancillary one. These members of staff have been very carefully decided upon over a period of time under work study conditions by management consultants. For 40 patients, there is a sister-in-charge and two other sisters, all three of whom have done post-graduate training in paraplegic nursing. In addition, there are approximately six to eight junior sisters undertaking post-graduate training, with 14 nurses to assist them. There are eight orderlies trained in the techniques of turning and posturing spinal injuries cases; five physiotherapists and one occupational therapist. A senior medical social worker devotes much of her day to the social problems involved. The author has a senior secretary who has administrative responsibilities to the unit. In addition, there is a records secretary and a receptionist-telephonist. In the year 1966-67, because of a long-felt need, a clerical research assistant was appointed, with the result that some further work has been undertaken, e.g. a paper on experience in the reconstruction of the quadriplegic hand, and a clinico-pathological study of patients with traumatic paraplegia in collaboration with Dr. Kakulas.

Finally, in 1965 the hospital appointed an education officer, who has considerable responsibility for patients in the younger age-groups. We are now satisfied that this is the definite minimum of staff required to enable a centre of this size to function effectively. 


\section{PATIENT CARE AND PROCEDURE}

The unit now accepts acute patients. All patients brought into Royal Perth Hospital with an acute spinal injury are seen in the casualty department and resuscitation unit of the hospital for careful assessment by the consultant on duty. Those patients who need major surgery (almost nil), or who are too ill to be transferred, are immediately taken to the intensive care ward for definitive action over a period of 48 hours before being transferred to the spinal unit. Those who do not need any acute surgical management are immediately transferred to the spinal unit, and thus arrive in the unit where adequate facilities are available within a matter of hours after the original injury. The patients then graduate through the ward areas from 'acute' to 'long stay' to 'self-care' and finally home or to other institutions. This early admission of cases is a unique situation shared by the Melbourne unit.

The genito-urinary service is under the direct care of a trained urologist. This trained urologist works three half-sessions per week in the spinal paralysis service. These sessions consist of consultations, ward rounds, and the use of a properly established urology theatre which at first was situated at Royal Perth Hospital as part of the urology department, but with the passage of time the Royal Perth Rehabilitation Hospital at Shenton Park has developed independent facilities for cystoscopy, panendoscopy, and all the investigatory services that are necessary for X-rays associated with such activities: intravenous pyelograms, retrograde cystoscopy, retrograde pyelograms and urethrograms.

Each week the urologist does a consultative round with the director of the department, when the different problems of urology are thoroughly discussed in relationship to the other methods of management in use.

Out-patients have therapy, e.g. catheter change, undertaken regularly by the resident medical staff on a particular day in the treatment room of the paraplegic unit. Whilst this treatment room was not designed as a theatre, it functions as a sterile area for all manner of procedures.

A great deal of emphasis is placed on the overall urological management of the patient, and this is taken care of in the various departments, e.g. in the nursing section special emphasis is placed on training of the bladder and its management. In the physiotherapy and occupational therapy sections, special emphasis on activity in relationship to urinary function is made. The overall control of management is at all times under the director of the unit, but the urologist has constant contact with all members of the team at the ordinary staff conferences which are held regularly once each week.

A very strict urological training programme is laid down for each patient, and is clearly understood by the nursing, physiotherapy, occupational therapy, and medical staff.

\section{NURSING}

Whilst the paraplegic unit is staffed as above, it has no major special equipment. The beds are ordinary hospital beds adapted in an orthopaedic style with overhead bars for independency and self-help. These bars are fitted with ropes and pulleys for resisted work; hence the work of the physiotherapist is con- 
siderably enhanced, while the patient's independency is stimulated. If necessary, the beds are fitted with rubber matresses to enable nursing of difficult pressure areas. These rubber blocks are now supplied by the Dunlop Rubber Company, but were originally made by cutting old mattresses into suitable shapes, then glueing them together and covering with a mackintosh and sheeting.

The important principle in all nursing management of paraplegics is regular turning, regular positioning, and the avoidance of pressure on any pressure area. At times this is extremely difficult and calls for a considerable amount of ingenuity.

\section{PHYSICAL THERAPY}

Physiotherapy staff consists of one senior therapist and four assistants. This staff is responsible for round-the-clock physiotherapy of acute cases, for all ward gymnasium activities, and for all sporting activities which are an essential part of the training period.

Occupational therapy is carried out in the main occupational therapy department of this rapidly developing rehabilitation hospital. Here all manner of activities are available, including workshop training and careful hand rehabilitation programmes. One therapist is particularly involved with vocational activities, which are also partly the responsibility of the social worker, who works in close liaison with therapists and the various Government agencies available.

\section{GENERAL}

The unit is run by the close-knit team-work of the two groups with the author as chairman. He expects and obtains much from them, and is therefore happy to be associated with such dedication. Mediocre work in spinal paralysis is not to be tolerated.

Each week there is a concise ward conference of all regular team members, at which problems are frankly and clearly discussed. Major rounds are undertaken at least twice per week; each third week a grand round is conducted, where two cases are thoroughly discussed by all and constitutes a post-graduate teaching session of some importance.

Other teaching responsibilities include:

(a) Medical students weekly.

(b) Two post-graduate courses are conducted each year, in which six to eight nurses on each course receive six months' training in the techniques of nursing spinal injuries.

This has resulted in the dissemination of information in Australia and in Asia, where some effort has been made to help establish units in India, Singapore, Hong Kong and New Zealand with aid from the Commonwealth Government and private funds.

\section{EXTRA-HOSPITAL CARE}

Very soon after admission, patients are introduced to the Paraplegic Association of Western Australia, an organisation which commenced in a very small way 


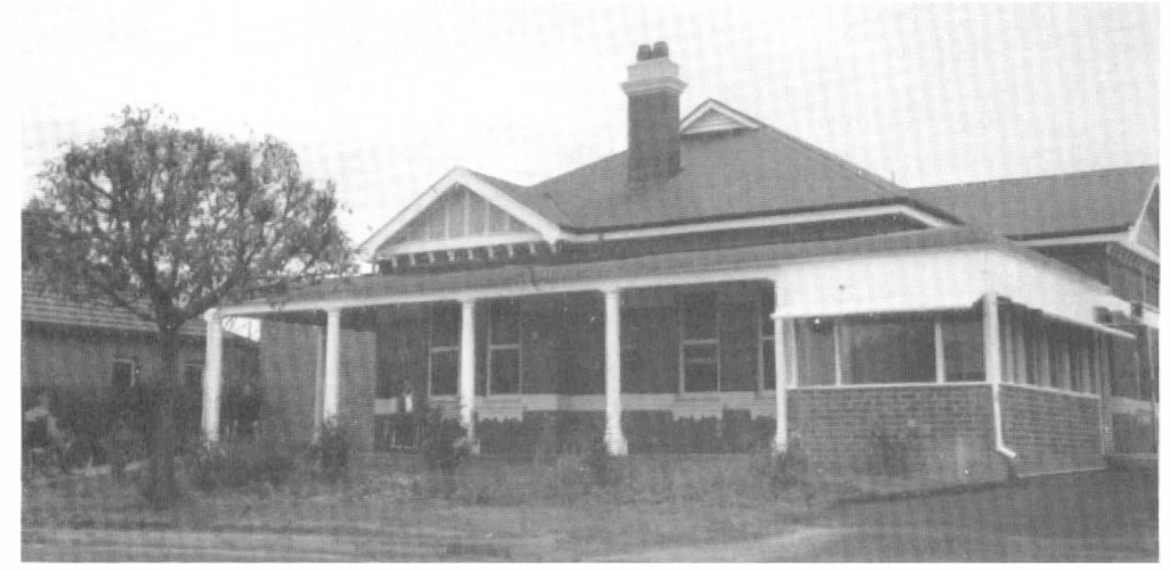

FIG. 4

Paraplegic Hostel.

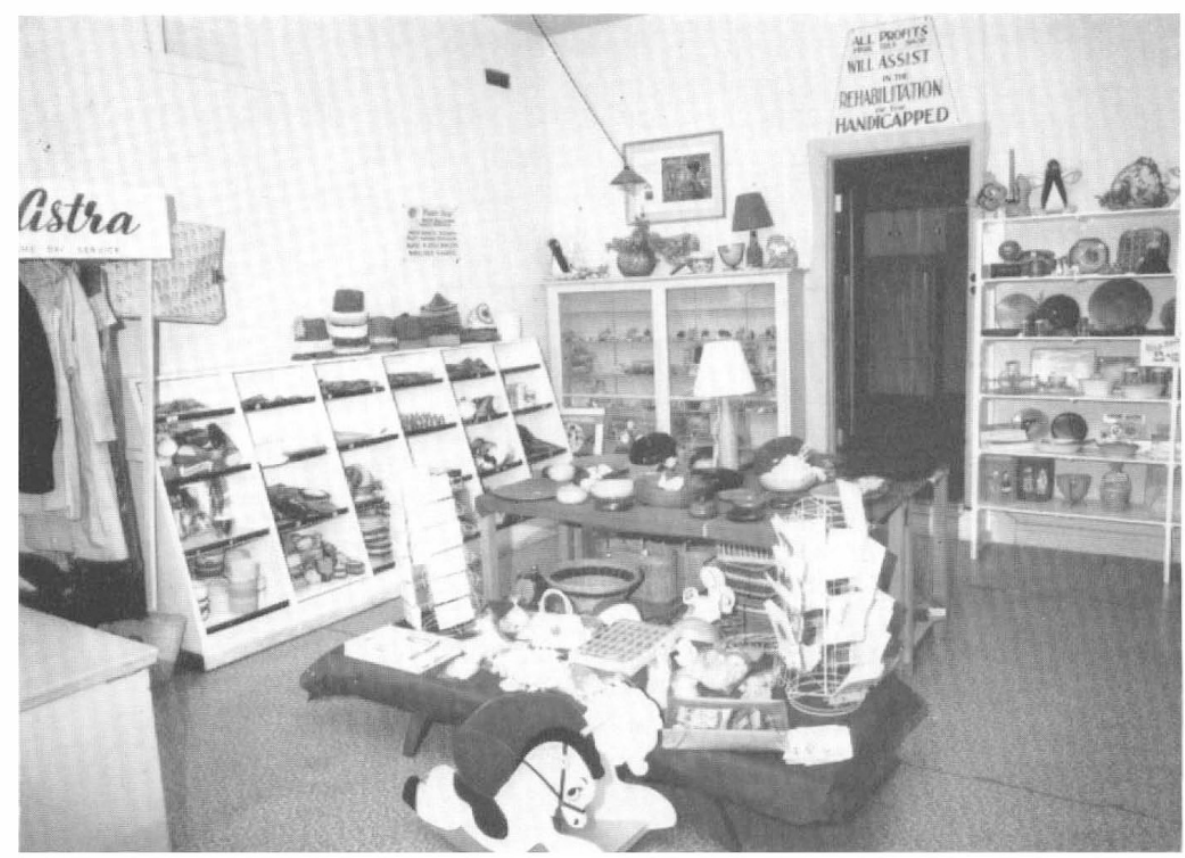

FIG. 5

Paraplegic Industries (interior) run by the Paraplegic Association of Western Australia. 
in 1956. The Executive Director is now regarded as part of the hospital team, although the Association is quite autonomous. This voluntary body now runs a paraplegic hostel; a centre for industry, and has active committees for finance, welfare, ladies' auxiliary, sports, and the hostel. Because of the help given in rehabilitation, this Association receives a subsidy from a very helpful State government; without it our patient-care programme in Western Australia would be greatly curtailed, for through this group comes industries, motor vehicles, homes, and social help in many ways.

The unit also fosters a close liaison with the Commonwealth Rehabilitation Service through its senior medical officer, with distinct advantages to both the patient and medical staff. When sufficiently independent, patients who qualify can be transferred to the modern Commonwealth Government Rehabilitation Centre at Melville.

It would not be fitting to close this paper without stressing the tremendous need for post-hospital care. At Royal Perth Hospital this is undertaken in two ways:

I. An out-patient service and follow-up. This is by appointment, and is the responsibility of a receptionist to see that each patient is reviewed regularly. If a patient fails to report for review, he or she is contacted and, if necessary, a social visit is made.

2. A second most important part of post-hospital management is that carried on by the Paraplegic Association, which has as its aims:

(a) the further rehabilitation of the paraplegic;

(b) the establishment of hostels and halls of residence;

(c) the establishment of workshops;

(d) further hospitalisation care as required.

Without such activities it would be very difficult for the paraplegic to remain adequately rehabilitated. The domestic care of the paraplegic and quadriplegic is a subject which must ever be an important part of the medical programme as supervised by a paraplegic unit. Thus, throughout the whole of the patient's management in hospital, great emphasis is placed on the patient and his or her home. Extensive social histories are taken on admission to hospital, and as rehabilitation proceeds, every care is taken to see that adequate domestic arrangements are possible.

Most patients of course are then able to go home, but many (in Western Australia about Io to I5 per cent. of paraplegics, and about 50 per cent. of quadriplegics) find that they must take up domestic residence in suitable hostels or in homes for the severely disabled. Undoubtedly, in many parts of the world these homes will have to cater much more adequately for patients than is necessary in Western countries.

In Western Australia the need for a quadriplegic hostel has now been well recognised, and in 1967-68 it is planned to build such a hostel on a block of land adjacent to the Royal Perth Rehabilitation Hospital. This hostel will be administered by the Paraplegic Association of Western Australia, expressly for the quadriplegic patient who cannot return home. With the aid of further research and further information, attempts must be made to rehabilitate the quadriplegic back to his own domestic scene. 
The author feels certain that paraplegics are best served by being treated completely in a special unit of a general hospital. This special unit should be able to call for assistance from outside rehabilitative units. It is not in the best interests of paraplegics that their early care in the first five or six months should be undertaken in non-specialised units such as orthopaedic, neurosurgical, urological, rehabilitative, or medical, for they cannot receive the especially co-ordinated service that, in many parts of the world, has been proved to give the best results.

\title{
THE FUTURE
}

So much for the present-what will the future hold? The author believes that the following will be needed in the years to come:

I. In Western Australia a full-time medical director will undoubtedly be required for the spinal injuries service.

2. The management of spinal injuries in Australia should ultimately become an independent speciality.

3. The need for wider research facilities must be met, particularly with regard to bladder physiology.

4. The scope of social work will have to be considerably expanded.

5. A steady improvement in the management of spinal injuries to the point where complications virtually disappear.

6. An even more adequate rehabilitation of quadriplegics than at present.

7. Finally, of great importance, more determined efforts must be made towards the prevention of spinal injuries. This can be undertaken with the co-operation of Road Safety Councils, Health Councils, etc., and must become an important part of the overall care.

\section{REFERENCES}

Bedbrook, G. M. (I963). A survey of the treatment of paraplegia and the results. Part IHospitalisation. R. Perth Hosp. F., March. Part II-Post hospitalisation. R. Perth Hosp. $\mathcal{F}$., June.

Bedbrook, G. M. (I964). Spinal paralysis: the present position. Rehabil. Aust., July, p. 3-6.

Commonwealth Social Services Handbook of Information.

Rossier, A. (1963). The organisation and function of the Spinal Cord Injury Service of the Veterans Administration Hospital, Long Beach, California. $\mathcal{F}$. int. Coll. Surg. 39, 225-237.

\section{FIFTEEN YEARS' EXPERIENCE ON REHABILITATION OF PARAPLEGICS AT THE REHABILITATION INSTITUTE OF WARSAW UNIVERSITY, POLAND}

\author{
By Professor Marian WeIsS \\ Rehabilitation Institute of the Warsaw School of Medicine at Konstancin
}

IN 1949 in Konstancin, near Warsaw, a Centre for Rehabilitation of Paraplegics has been created within the Institute for Rehabilitation, starting at that time with 